\title{
Work-flow to establish a conceptual model of soil-plant relationships in salt marshes: a case study in SE Spain
}

\author{
Maria Nazaret González-Alcaraz, José Álvarez-Rogel \\ Departamento de Ciencia y Tecnología Agraria. Área de Edafología y Química Agrícola, \\ E.T.S. de Ingeniería Agronómica, Universidad Politécnica de Cartagena, \\ Paseo Alfonso XIII, 48, Cartagena, 30203 Murcia, Spain \\ e-mail: mnga@upct.es
}

\begin{abstract}
Summary. In this study we describe the steps followed to elaborate a conceptual model of soil-plant relationships in a salt marsh: 1) identify vegetation distribution; 2) obtain soil data; 3) study the characteristics of the salinity; 4) analyze the relationships among soil factors; 5) understand soil-plant relationships; 6) elaborate the conceptual model.
\end{abstract}

Key words: plant zonation; soil-plant relationships; environmental gradients.

\section{Introduction}

There are many reports that have shown relationships between plant communities and environmental factors (e.g. Álvarez-Rogel et al. 2000). Although it was early demonstrated that biotic interactions are partly responsible for plant zonation in salt marshes, the knowledge of the relationships among species distribution and soil conditions permits establish conceptual models that may help the management of wetlands and salt marshes. This kind of studies requires follow some steps and know several key aspects about the possible work-flows. This study describes these steps based on a study developed in a coastal salt marsh of SE Spain (Álvarez-Rogel et al. 2006).

\section{Study area}

The study area was located in a dune system in the Regional Park of Salinas y Arenales de San Pedro del Pinatar

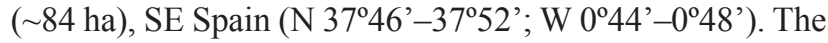

climate is typically Mediterranean. Landscape positions in the dune system include the summit of the dunes (the topographically highest sites) and the interdune depressions. The existence of a saline groundwater salinizes the soils, which are classified as Arenosols at summit positions and Gleysols or Solonchaks at interdune depressions.

\section{Research methods}

1. Vegetation. Prior to soil sampling, aerial images were used and field observations were made in order to identify different stands of vegetation and their distribution. The stands were recognized according to the dominant species. Due to the spatial distribution of the vegetation in a "mosaic", the use of transects was not accurate and a stratified random sampling design was used with a total of 82 plots (surface $5 \times 5 \mathrm{~m}^{2}$ ). Floristic composition and species abundance were determined in each plot (at last 5 plots for each type of vegetation) using the standard method of relevés (Westhoff \& Maarel 1978) 
2. Soil. Surface soil samples were taken from each vegetation plot in spring and summer. In addition, five plots were located in bare soils. Three cores for each sample were taken from the top $20 \mathrm{~cm}$ and then mixed. The groundwater level (less than $1.5 \mathrm{~m}$ deep) and the depth at which a dark grey horizon (depleted matrix according to USDA-NRCS 2003) appeared were obtained in wells excavated in the same three points in spring and summer. The distance to the shoreline was measured for each plot.

3. Analysis. A 1:5 soil:water suspension was made for each soil sample and electrical conductivity and soluble $\mathrm{Ca}^{2+}, \mathrm{Mg}^{2+}, \mathrm{Na}^{+}, \mathrm{K}^{+} \mathrm{HCO}_{3}^{-}, \mathrm{Cl}^{-}, \mathrm{SO}_{4}^{2}$ were measured. Moisture was determined gravimetrically.
4. The steps followed to analyze the data set included: 1) the study of the characteristics of the salinity and its relationships with electrical conductivity (correlations and regressions); 2) the study of the relationships among the different soil factors (correlations and regressions); 3) the identification of the physical gradients and its relationship with plant distribution (principal component analysis, PCA); (4) the establishment of the conceptual model in order to use the species to monitor changes in soil conditions.

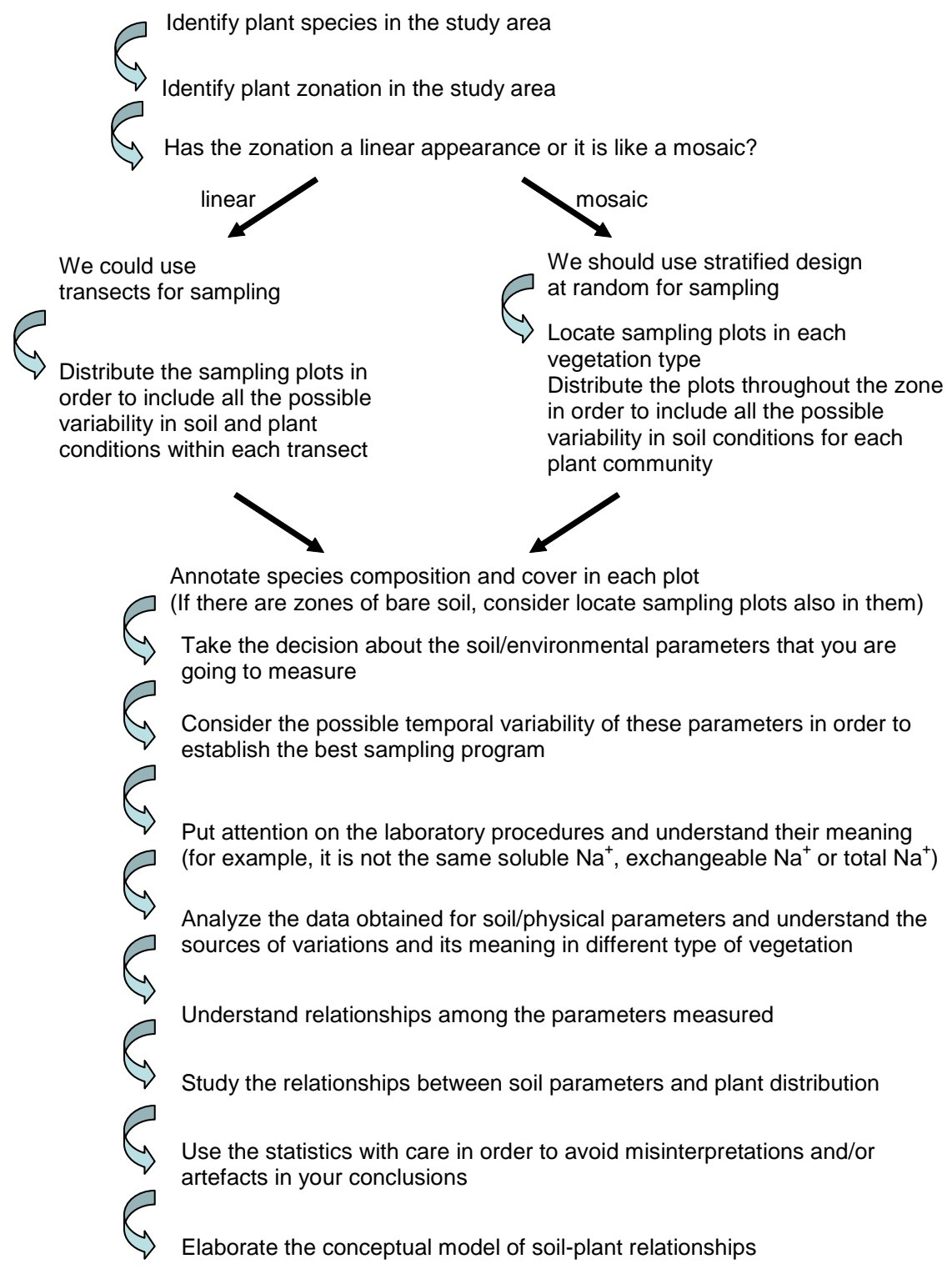

Figure 1. Work-flow for analyzing soil-plant relationships 


\section{Results}

Figure 1 shows the work-flow followed to study soil-plant relationships in the study site. Soils at interdune depressions were consistently more saline, wetter, and with a shallower water table and gleyed matrix than soils at summit positions. Soil moisture, salinity, and the distance to the shoreline were parameters related to plant distribution at summit positions. However, at interdune depressions species distribution was mainly related to salinity, moisture, depth of the groundwater, and depth to gleyed matrix.

\section{References}

Álvarez Rogel J., Alcaraz Ariza F. \& Ortiz Silla R., 2000, Soil salinity and moisture gradients and plant zonation in Mediterranean salt marshes of Southeast Spain, Wetlands 20: 357-372.
Álvarez Rogel J., Jiménez-Cárceles F. J., Roca M. J. \& Ortiz R., 2007, Changes in soils and vegetation in a Mediterranean coastal salt marsh impacted by human activities. Estuarine, Coastal and Shelf Science 73: 510-526.

Álvarez Rogel J., Martínez Sánchez J. J., Carrasco Blázquez, L. \& Marín Semitiel C., 2006, A conceptual model of salt marsh plant distribution in coastal dunes of Southeastern Spain, Wetlands 26: 703-717.

U.S. Department of Agriculture, Natural Resources Conservation Service, 2003, Field Indicators of Hydric Soils in the United States, Version 5.01. G. W. Hurt, P. M. Whited, \& R. F. Pringle (eds.) USDA, NRCS in cooperation with the National Technical Committee for Hydric Soils, Fort Worth, TX, USA. Valde's, B., Talavera S.

Westhoff V. \& van der Maarel E., 1978, The Braun Blanquet Approach, [in:] Classification of Plant Communities, second edition R. H. Whittaker (ed.), Dr. Junk, The Hague, The Netherlands: 287-399. 